\title{
ANÁLISIS DISCURSIVO FUNCIONAL DE UN FRAGMENTO DE TEXTO COLOQUIAL
}

\author{
Olaysi Arrocha Rodríguez ${ }^{1}$ \\ Zuleiny Meneses Martin ${ }^{2}$ \\ Amyra García Rodríguez ${ }^{3}$
}

Universidad de Ciego de Ávila Máximo Gómez Báez (Cuba)

Recibido 04/01/2021 Aceptado 01/06/2021

Las concepciones acerca del discurso, cobran cuerpo en lo actualmente se denomina lingüística del habla, que se alcanzaron como resultado de los aportes de las ciencias que, en sus respectivos campos, asumieron los problemas referidos a la comunicación, la cognición y los usos del lenguaje en diferentes contextos. El análisis discursivo-funcional, planteado desde el enfoque cognitivo, comunicativo y sociocultural, posee sus basamentos en tres principios metodológicos: el principio de la orientación hacia un objetivo, el principio de la selectividad en el análisis y el principio de la enseñanza del análisis. Se aborda el tratamiento metodológico para el análisis discursivo funcional que cuenta con diferentes operaciones y tres fases: introductoria, de comprensión y análisis y de construcción de nuevos discursos.

5 Conceptions about discourse take shape in what is currently called speech linguistics, which were achieved because of the contributions of the sciences that, in their own fields, assumed the problems related to communication, cognition and the uses of language in different contexts. The discursive-functional analysis, raised from the cognitive, communicative and sociocultural approach has its bases in three methodological principles: the principle of orientation towards an objective, the principle of selectivity in the analysis and the principle of teaching analysis. The methodological treatment for functional discursive analysis is addressed, which has different operations and three phases: introduction, understanding and analysis, and construction of new discourses.

Análisis; Comprensión; Construcción de discursos. 


\section{INTRODUCCIÓN}

En la actualidad, se considera que "el lenguaje hablado, señalizado o escrito, que usan las personas para comunicarse en situaciones naturales, es el ámbito apropiado para estudiar las gramáticas de las lenguas del mundo, por ser no solo el lugar donde la gramática se pone en uso, sino también la fuente a partir de la cual se forma o "surge" la gramática". Desde esa perspectiva, "la gramática se origina en los patrones recurrentes en el discurso, y estos patrones continuamente la configuran”. (Casado Velarde, 1993).Se abren nuevas vías de análisis del discurso: el análisis discursivo-funcional.

El enfoque discursivo-funcional lo hemos conocido en Cuba también como "descripción comunicativo-funcional del texto" (Callejas, 1989). Dicho enfoque tiene dos objetivos: describir y explicar. El objetivo descriptivo se logra cuando se analizan los recursos gramaticales de que dispone una lengua y que permiten expresar un mismo significado de forma diferente. Aquí la reflexión metalingüística gira en torno a las siguientes interrogantes: ¿Qué estructura gramatical es? ¿Cuál es su función y cómo puede alternar con otras?; ¿Por qué el autor eligió esta y no otra estructura?

El objetivo explicativo posibilita la reflexión acerca del elemento topicalizado, la coherencia, la pertinencia y otros fenómenos propios de la sintaxis discursiva, su relación con la intención comunicativa del autor, teniendo en cuenta lo que quiere significar y el contexto social en el cual la significación tiene lugar.

Las explicaciones se originan de forma interrelacionada durante el proceso de análisis y podrán ser de tres tipos:

a) explicaciones gramaticales, que tienen en cuenta el análisis de los recursos fónicos, léxicos y gramaticales propiamente dicho, así como sus valores estilísticos y retóricos (sintaxis del texto);

b) explicaciones cognitivas, que se refieren a los procesos cognitivos mediante los cuales los interactuantes comprenden y producen significados (semántica del texto), que ponen al descubierto el contexto y las situaciones comunicativas en las que tiene lugar la comunicación oral y escrita;

c) también las intenciones y características socioculturales de los interactuantes (pragmática del texto).

Esto no está suficientemente explicado, pues el contexto sociocultural y el cognitivo es el mismo, está depositado en la conciencia de los hablantes o el receptor y el emisor, su desglose es metodológico; pero su mecanismo requiere de más precisión.

Tales explicaciones giran en torno a los componentes del llamado triángulo del discurso (Van Dijk, 2000), que revela el carácter interdisciplinario, y transdisciplinario del análisis al integrar los saberes multidisciplinarios que el analista posee de diferentes discipli- 
nas, como son la Gramática del texto, la Psicología cognitiva, la Semántica, la Sociolingüística y la Pragmática, sin olvidar otros saberes esenciales referidos al conocimiento del mundo y que aportan otras ciencias.

En el análisis discursivo funcional, cada uno de los niveles del plano formal del texto se correlaciona con los niveles de estructuración del significado que se revelan en el plano del contenido: desde las microproposiciones, a las macroproposiciones y los significados globales que conforman dicho plan. Al orientar a los alumnos en la comprensión, análisis y construcción de discursos es necesario que sistematicen las operaciones siguientes:

- Leer el texto seleccionado (oral y en silencio).

- Esclarecer las incógnitas léxicas (palabras desconocidas).

- Ubicar el texto y su autor en el contexto histórico.

- Identificar las palabras-clave, las redes de palabras, los conectores y otras estructuras léxicas y gramaticales empleadas intencionalmente por el autor.

- Extraer las ideas principales y secundarias, los modelos de progresión temática, la coherencia y otras características de la textualidad.

- Elaborar nuevas proposiciones, a partir del pensamiento inferencial y atribuirle significado al texto.

- Inferir la intencionalidad y finalidad del autor según el contexto y su ideología.

- Identificar los actos de habla.

- Determinar tema, subtemas, macroproposiciones, tesis y argumentos.

- Representar mediante íconos o esquemas las ideas contenidas en el texto.

- Resumir la tesis y el problema contenido en el texto. Tenga en cuenta el tipo de texto que analiza.

- Atribuir nuevos significados al texto.

- Valorar críticamente el texto.

- Elaborar una reseña del texto en la que se valoren críticamente las ideas del autor.

- Reflexionar acerca de la vigencia de las ideas y su aplicación en contextos similares o en otros contextos.

- Escribir breves ensayos sobre problemas reflejados en el texto que hayan suscitado esas reflexiones.

En el proceso de comunicación, el análisis opera como una interfaz entre los procesos de comprensión y construcción de textos. 
Durante el análisis, ofrecemos explicaciones semánticas, sintácticas y pragmáticas. Analizar es, pues, describir y explicar los contenidos de un texto, es decir, comentar las ideas y conceptos que en él se expresan y también, revelar la intención del autor y las relaciones que existen entre esas ideas y conceptos, es decir, su estructura argumentativa; de igual forma, el análisis implica la valoración.

El análisis de la estructura del discurso en su dimensión social, no puede reducirse al análisis de oraciones aisladas, desvinculadas de los procesos cognitivos y de la interacción, como lo ha hecho tradicionalmente la gramática formal, sino que responden a la lógica de la organización semántica y a su adecuación al contexto. (Van Dijk, 2000) introduce los términos de macroestructura semántica (MES) y macroestructura formal (MEF), que dependen de un criterio organizativo superior: la superestructura esquemática del discurso (SEE) y del contexto. El análisis discursivo funcional del discurso debe abordar, de forma integrada, las dimensiones semántica, sintáctica y pragmática del texto.

Las concepciones actuales acerca del análisis discursivo funcional del discurso tienen en cuenta las interrelaciones entre la MES (conceptos, microproposiciones, macroproposiciones y tema) y la MEF (sintagma, oraciones, segmentos o párrafos y texto), enmarcadas en el contexto. En este proceso, se descubren las características de la textualidad: coherencia, cohesión, informatividad, aceptabilidad situacionalidad, intertextualidad (Beaugrande, 2000), y otras como la progresión temática, la pertinencia y la búsqueda del texto acabado (Núñez y Del Teso, 1996). La textualidad, según (Beaugrande, 2000) es "un logro humano en materia de hacer conexiones dondequiera que tengan lugar acontecimientos comunicativos".

La característica fundamental de la textualidad es la coherencia, cuyo análisis descansa en la concepción integradora por la que abogamos, que comprende el análisis integrado de la coherencia semántica, la coherencia formal o cohesión y la coherencia pragmática.

Sobre la base del análisis de la cohesión se hace evidente la funcionalidad de los medios empleados por el autor (referentes, anáforas, elipsis, conectores, orden de las oraciones y otros), que garantizan la estructuración coherente del texto en sus diferentes niveles: desde las microestructuras hasta las macroestructuras y la superestructura esquemática del texto. Cada uno de estos niveles del plano formal del texto se correlacionan con los niveles de estructuración del significado que se revelan en el plano del contenido: desde las microproposiciones, a las macroproposiciones y los significados globales que conforman dicho plan.

Todo intento de aproximación al análisis del discurso implica al menos tres fases o momentos: la prelectura que comprende la preparación, la lectura, que implica la comprensión y análisis y la post-lectura, que comprende la construcción de nuevos discursos.

El análisis discursivo funcional no responde a un esquema rígido, pero las operaciones siguientes pueden servir de guía para su realización en cada fase: 
Fase introductoria:

- Leer el texto seleccionado (oral y en silencio).

- Identificar el tipo de texto (código, forma elocutiva, función estilo).

- Esclarecer las incógnitas léxicas (palabras desconocidas).

- Ubicar el texto y su autor en el contexto histórico.

Fase de comprensión y análisis:

- Dividir el texto en partes lógicas.

- Identificar las palabras-clave, las redes de palabras, los pronombres, los deícticos, los conectores y otras estructuras léxicas y gramaticales empleadas intencionalmente por el autor y su relación con la intención comunicativa del autor.

- Aplicar estrategias de inferencia (intención comunicativa del autor, causas y consecuencias del texto, etc.).

- Explicar la funcionalidad de dichas estructuras en el texto, a partir de lo que se significa y el contexto en el que se significa.

- Identificar en el texto las características de la textualidad: coherencia, cohesión, progresión temática, pertinencia cierre semántico, intertextualidad y otras.

- Extraer las ideas principales y secundarias, los modelos de progresión temática empleados por el autor, la coherencia, la pertinencia, el cierre semántico, la intertextualidad y otras características de la textualidad.

- Inferir la intencionalidad y finalidad del autor según el contexto y su ideología.

- Elaborar nuevas proposiciones, a partir del pensamiento inferencial y atribuirle significado al texto.

- Determinar conceptos, microproposiciones, macroproposiciones, subtemas, tema, tesis y argumentos.

- Representar mediante íconos, mapas conceptuales o esquemas las ideas contenidas en el texto.

- Resumir la tesis y el problema contenido en el texto.

- Atribuir nuevos significados al texto

- Valorar críticamente el texto.

Fase de construcción de nuevos discursos:

- Elaborar un comentario o reseña del texto, donde se valoren críticamente las ideas del autor y se revelen las relaciones entre las dimensiones semántica, sintáctica y pragmática. 
- Reflexionar acerca de la vigencia de las ideas y su aplicación en contextos similares o en otros contextos lo que hace al texto intertextual.

- Escribir breves ensayos sobre problemas reflejados en el texto que hayan suscitado esas reflexiones.

El análisis discursivo-funcional, tal como se plantea desde el enfoque cognitivo, comunicativo y sociocultural (Roméu, 2003), descansa en tres principios metodológicos: el principio de la orientación hacia un objetivo, el principio de la selectividad en el análisis y el principio de la enseñanza del análisis.

Los estudiantes de la carrera Español- Literatura reciben en su plan de estudios la asignatura Análisis del Discurso a partir de los diferentes estilos funcionales. El presente trabajo aborda el tratamiento metodológico para analizar textos y se ejemplifica a través de un fragmento del cuento ;Diles que no me maten! de Juan Rulfo:

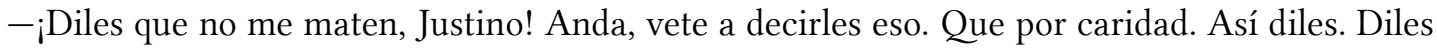
que lo hagan por caridad.

-No puedo. Hay allí un sargento que no quiere oír hablar nada de ti.

- Haz que te oiga. Date tus mañas y dile que para sustos ya ha estado bueno. Dile que lo haga por caridad de Dios.

-No se trata de sustos. Parece que te van a matar de a de veras. Y yo ya no quiero volver allá.

-Anda otra vez. Solamente otra vez, a ver qué consigues.

-No. No tengo ganas de ir. Según eso, yo soy tu hijo. Y, si voy mucho con ellos, acabarán por saber quién soy y les dará por fusilarme a mí también. Es mejor dejar las cosas de este tamaño.

-Anda, Justino. Diles que tengan tantita lástima de mí. Nomás eso diles.

Justino apretó los dientes y movió la cabeza diciendo.

- No.

Y siguió sacudiendo la cabeza duramente mucho rato.

\section{DESARROLLO}

El texto en análisis pertenece al cuento: ¡Diles que no me maten!, escrito por el autor mexicano, Juan Rulfo. Fue redactado en México, en la primera mitad del siglo XX, donde existía un contexto complejo marcado por protestas sociales, ruralismo, ambiente arrabalero, debido a políticas y gobiernos corruptos. Caracteriza la obra de este autor la penumbra en la que se vivía, paisajes oscuros, secos, miserables, que reflejan las clases más desposeídas de la sociedad mexicana. Varios críticos afirman que este autor fue capaz de reflejar estos sucesos tan sombríos porque formaron parte de su vida. Su padre fue asesinado desde que él tenía solo siete años y su madre muere dos años más tarde, quedando 
al cuidado de una abuela. Su obra se encuentra dentro del movimiento del realismo, donde se asume una actitud ante la realidad y se lleva a los escritos con personajes y hechos que encarnan situaciones ficticias con una base socialmente reconocida como real teniendo en cuenta la historia del pueblo mexicano.

En el cuento intervienen: Juvencio Nava, quien es el sentenciado por un crimen cometido hacía muchos años atrás, su hijo Justino, y el coronel quien fuera hijo del asesinado don Lupe. En este se narra cómo fue la vida de Juvencio, después del suceso, y finalmente es capturado y atado a un horcón como un animal, hasta que lo matan cruelmente. En el tiempo que trascurre vivo en esa situación pide, implora, a su hijo que interceda por él ante el coronel, para que le dejen en paz, pues considera que ya ha pagado en vida el daño que hizo con don Lupe. El hijo no puede interceder pues teme correr con la misma desgracia del padre y tenga que dejar a su mujer e hijos sin amparo. El coronel sentenciador resulta ser el hijo pequeño que había dejado don Lupe muchos años atrás, y siendo la autoridad en ese momento se venga sin piedad y agujerea el cuerpo del Juvencio hasta que queda irreconocible. La resignación es la única solución posible para Justino ante el hecho.

El texto seleccionado pertenece al estilo coloquial que presenta las siguientes características:función meramente comunicativa, carácter incompleto del enunciado, tanto desde el punto de vista de su forma, como desde el de su contenido, automatismos conversacionales o coloquiales, uso de medios de expresión extralingüísticos tales como los gestos, los ademanes, la mímica, uso de modelos emocionales de entonación, frecuente uso de oraciones unimembres, economía de los medios de expresión, espontaneidad, naturalidad y sencillez, estilo directo, concreto, preciso y el uso de un lenguaje figurado. Fluye en este el diálogo con un lenguaje aparejado a la norma lingüística de México pero que es entendible a los hablantes del habla hispana. El fragmento escogido es el que encabeza la narración, después de titularlo.

El cuento: ¡Diles que no me maten!, de Juan Rulfo, narra una historia ficticia que puede haber estado reflejada en cualquiera de los habitantes mexicanos en ese contexto, después de la postguerra. En el texto se utiliza el estilo coloquial. Se establece la conversación como forma fundamental de los textos dialogados, lo que permite hacerlo más atractivo al lector al utilizar un lenguaje propio de la comunidad lingüística, que permite además, relatar en boca de los personajes una situación dada, favoreciendo el conocimiento del argumento.

El título seleccionado para este cuento ;Diles que no me maten!, es muy sugerente para captar la atención del lector desde el primer momento. Esta construcción exclamativa, es una oración compuesta por subordinación sustantiva. Teniendo en cuenta la actitud del hablante es negativa y se utiliza el modo imperativo de ruego, comenzando por el verbo diles, que posee como intención comunicativa implorar por parte del sentenciado que no lo asesinen, lo que denota su carácter concreto, sin subjetividades, ante una situación de peligro para la vida del hablante, y predomina la función conativa. 
Aparecen en el fragmento seleccionado los turnos de palabra donde fluye una conversación espontánea teniendo en cuenta "el ciclo de emisión-interpretación de significados de forma disciplinada y lógica dentro del proceso de producción que se establece desde el punto de vista dialógico". (Tusón, 2002). Esto facilita la comprensión adecuada de cada parte, por el lector, pudiendo hacer un juicio valorativo de las ideas que se expresan por cada uno de los hablantes. La conversación se separa por el guion intercalando las expresiones hechas por los dialogantes. Se precisa que la conversación es espontánea donde se ponen de manifiesto los rasgos del carácter, el temperamento de los hablantes teniendo en cuenta la situación en la que se encuentran, su educación, a qué clase social y grupo pertenecen, cómo piensan y cómo actúan.

En la primera oración psicológica ( Diles que no me maten, Justino! Anda, vete a decirles eso. Que por caridad. Así diles. Diles que lo hagan por caridad), se alude por parte del Juvencio a su hijo Justino, utilizándolo como vocativo, para que este interceda por él en la sentencia que le han reservado. Predomina el modo imperativo, en forma de ruego, clemencia, piedad con la utilización de verbos imperativos como: diles, anda, vete, con lo cual el lector puede captar con facilidad el marco en que se desarrolla el relato. El tono es exclamativo, pero de angustia, desesperación. Se vale de construcciones sintácticas separadas por puntos para suplicar, como por ejemplo: ¡Diles que no me maten, Justino! Presentándose una oración compuesta por subordinación sustantiva al igual que cuando expresa: (Diles que lo hagan por caridad), véase cómo el autor se vale de este tipo de construcción para pedir con extremado énfasis lo que necesita que su hijo haga por él.

A este llamado su hijo responde después del punto y aparte, de forma contraria a lo deseado, utilizando la construcción sintáctica (No puedo), en solo dos palabras deja claro su posición ante los acontecimientos, construcción marcada por un sujeto omitido y la negación del hablante; después expone la justificación de su postura teniendo en cuenta el contexto (Hay allí un sargento que no quiere oír hablar nada de tí), obsérvese cómo se empleó una oración unimembre impersonal con un sintagma nominal que funciona como complemento directo y con una perífrasis modal con la intención de dar una explicación convincente al padre que intenta a toda costa lograr una acción en su beneficio, que para el receptor es en balde.

Sin embargo, el padre continúa su plegaria, esta vez con un tono más fuerte, que tiende a implorar, pero con una mayor imposición al receptor, y recurre para esto a una construcción sintáctica subordinada sustantiva, con un verbo en modo imperativo y un sujeto elíptico para no caer en repeticiones innecesarias. Sigue exponiendo mediante oraciones largas con carácter conativo lo que este debe hacer y cómo lo debe hacer para conseguir el propósito deseado, emplea la oración (Date tus mañas y dile que para sustos ya ha estado bueno), donde se ve evidenciado esa norma lingüística mexicana con la expresión "date tus mañas", propio del vocabulario popular para significar que invente, que resuelva poniendo en práctica habilidades que él sabe, para solucionar el problema. 
Fíjese además en la sintaxis de la oración, sujeto elíptico, donde sigue insistiendo al receptor con un matiz imperativo, y una coordinación copulativa para enlazar lo que se pretende, y luego una subordinada sustantiva para expresar argumentos de por qué él no debe estar en esa situación. Finalmente alude con una construcción compuesta por subordinación sustantiva, con un tono más desesperado para lograr influir por mediación de su hijo ante sus opresores valiéndose de Dios, pues el pueblo mexicano es muy creyente y tal vez por esta vía pudiera resolver dicha cuestión (Dile que lo haga por caridad de Dios).

El receptor continúa firme en su decisión de no interceder, al responder (No se trata de sustos. Parece que te van a matar de a de veras. $Y$ yo ya no quiero volver allá), donde se refleja el carácter objetivo, real de los sucesos, por mediación de una enunciativa negativa con la cual se logra enfatizar que es bien serio el asunto. Posteriormente, explica mediante construcciones compuestas el porqué cree que es cierto el penoso final que se le ha reservado, utilizando frases propias del pueblo mexicano "te van a matar de a de veras”, es decir, no es un juego, no te están asustando por gusto, van a actuar cuando sea el momento, por tanto, lo enfatiza mediante la perífrasis verbal incoativa (van a matar) que no tiene sentido volver allí a pedir por la vida de su padre.

Un poco desesperanzado, pero insistiendo aún, el padre expresa (Anda otra vez. Solamente otra vez, a ver qué consigues), toda la construcción encierra una sola idea, donde el sujeto se encuentra elíptico con una construcción yuxtapuesta,para lo cual utiliza el modo imperativo con un matiz de súplica con la intención de persuadir al coronel para que actúe a favor del desdichado, en lo que ya no se tiene mucha fe por parte del hablante, pero como "la esperanza es lo último que se pierde", insiste tratando de descifrar enigmas, basado en un tal vez, quizás, se pueda mejorar en "algo" a su favor.

El hijo, responde con un no, brindando una explicación más convincente al padre de por qué no puede ir a interceder por él, teme a correr con la misma suerte, al saber por parte de los oficiales, que este es su hijo. Para esto el autor se vale de construcciones extensas, compuestas explicativas, para convencer definitivamente a Juvencio. Apréciese aquí otra expresión del pueblo mexicano en la última oración expuesta (Es mejor dejar las cosas de este tamaño) con el objetivo de significar que es suficiente, que ya las cosas son graves, que no lo haga más difícil, porque pueden empeorar aún más, teniendo una mayor la repercusión. Por eso, se está en consonancia con lo expresado por Schiffrin (1991) “... el lenguaje siempre ocurre en un contexto y el lenguaje depende de un contexto...", porque a partir de esta situación dada es que se ponen de manifiesto estas frases escogidas con singular particularidad de acuerdo con ese contexto social.

El padre, expone después de esta respuesta, casi ahogado en la desesperanza, con tono apagado, doloroso, amargo (Anda, Justino. Diles que tengan tantita lástima de mí. Nomás eso diles). Con el objetivo de agotar hasta el último recurso posible para su salvación, se vale de una construcción psicológica en que se utiliza el sustantivo Justino en función de vocativo para pedir nuevamente al hijo que lo ayude a liberarse de la condena. Predomi- 
nan los verbos en modo imperativo igualmente a los anteriores, expresados por el padre. Se ponen de manifiesto expresiones populares como "diles que tengan tantica lástima de mí". Nomás eso diles", con la intención comunicativa de "por mediación de la lástima" que puedan tenerle a un ser humano los sentenciadores, mostrarse menos violentos con él, al fin y al cabo, ya era un pobre viejo que había pasado su vida en un suplicio.

Posteriormente, se expresa por medio del narrador una construcción enunciativa afirmativa, compuesta por coordinación copulativa donde Justino, utiliza el lenguaje no verbal a partir del código gestual, que posibilita comprensión de significados, (aprieta los dientes, mueve la cabeza negativamente) para significar que ya se cansó de exponer argumentos, que nada de lo que le diga lo va a convencer de ir a hablar para sacarlo de esa penuria porque es por gusto con los oficiales y el coronel. Y expresa finalmente un "no" contundente que muestra que no hay posibilidad alguna.

Termina el fragmento seleccionado, con una construcción con sujeto elíptico, continuación de la anterior intervención del narrador para significar el gesto prolongado de Justino en no estar convencido de ir a hablar con los guardias de ninguna forma posible, para que su padre se conformara con la sentencia y lo dejara tranquilo en consideración al peligro que podía correr él también. Estos medios extralingüísticos ayudan a la comprensión del texto de forma más precisa en los sucesos ocurridos, propiciando la creación de imágenes, que permiten apropiarse más claramente de lo vivido en ese contexto.

\section{CONCLUSIONES}

- El análisis discursivo-funcional, tal como se plantea desde el enfoque cognitivo, comunicativo y sociocultural descansa en tres principios metodológicos: el principio de la orientación hacia un objetivo, el principio de la selectividad en el análisis y el principio de la enseñanza del análisis. Se sugieren diferentes operaciones para la elaboración del análisis como: la fase introductoria, la fase de comprensión y análisis y la fase de construcción de nuevos discursos.

- En el texto analizado predomina la narración con un lenguaje coloquial, conversacional espontáneo que permite caracterizar a los personajes que intervienen y hacer juicios valorativos teniendo en cuenta texto - contexto. Predominan las oraciones compuestas con verbos en modo imperativo, cuyo matiz es de ruego, súplica. El tono varía: más o menos exigente, en dependencia de lo que se va desarrollando en el cuento. Se utilizan frases propias de la norma lingüística de la comunidad mexicana entendibles a los hablantes de habla hispana, lo que permite conocer con mayor profundidad la cultura lingüística de este pueblo. Se utiliza el código gestual que permite una mayor comprensión del texto analizado, propio de las características del lenguaje coloquial. 


\section{REFERENCIAS}

BEAUGRANDE, R. (2000): "La saga del análisis del discurso". En El discurso como estructura y proceso. Estudios sobre el discurso I, de Teun A. van Dijk (comp.). Gedisa. Barcelona.

CALLEJAS, D. (1989): La descripción comunicativo-funcional de la lengua en la enseñanza. Cuba: Universidad de Oriente, Santiago de Cuba.

CASADO, M (1993): Introducción a la Gramática del Texto del Español. Madrid: Editorial Arco/Libro.

GARCINI, MC. y MATOS, E. (1963) Antología del cuento hispanoamericano. Cuba: Editora del Ministerio de Educación.

NÚÑEZ, R. y DEL TESO, E. (1996): Semántica y pragmática del texto común. Cátedra, Madrid, España.

ROMÉU, A (2003): Teoría y práctica del análisis del discurso. Su aplicación en la enseñanza. Cuba: Ed. Pueblo y Educación.

VAN DIJK y TEUN A. (2000): El discurso como estructura y proceso. Estudios sobre el discurso I. Ed. Gedisa, Barcelona. 